\title{
O QUE NOS OLHA NOS OLHOS: O OLHAR DE ANTOINE
}

\author{
Carolina Vidal \\ Tiago Hermano Breunig \\ Mestre em Teoria Literária - UFSC
}

RESUMO: O conceito de montagem apropriado por Walter Benjamin a partir do cinema constitui, no contexto de uma crise cognitiva que acompanha a consolidação da modernidade capitalista, um modelo formal que, segundo o autor, permite restabelecer a experiência. A partir do referido conceito, associado ao distanciamento entre o sujeito e o objeto, propomos uma leitura do filme Les quatre cent coups (François Truffaut, 1959), sobretudo do congelamento do quadro final associado ao olhar transgressor do personagem Antoine Doinel, cujos olhos causam estranhamento ao cruzarem os do espectador.

PALAVRAS-CHAVE: Cinema; Montagem; Modernidade; Distanciamento.

\section{WHAT LOOKS AT US: ANTOINE'S EYES}

ABSTRACT: . The concept of montage appropriated by Walter Benjamin from cinema constitutes, in the context of a cognitive crisis that accompanies the consolidation of capitalist modernity, a formal model that, according to the author, enables the reestablishment of the experience. From the mentioned concept, associated to the distancing between subject and object, we propose a reading of the film Les quatre cent coups (François Truffaut, 1959), in particular about the freezing of the final shot associated to the transgressive look of the character Antoine Doinel, whose eyes cause estrangement when crossing the spectators.

KEYWORDS: Cinema; Montage; Modernity; Distancing. 
A cidade se espelha em milhares de olhos, em milhares de objetivas.

Walter Benjamin

Um olhar que consterna e que constrange na medida em que desnuda e solicita uma sensibilidade e, sobretudo, perpassa uma constelação de fatores que se imprimem no interior do globo ocular ao atingir os nossos olhos se manifesta nos olhos de um personagem. Antoine Doinel, ao interrogar constantemente os seus limites em Les quatre cents coups, representa um personagem recorrente da modernidade, em um filme que procura captar uma Paris na qual a Torre Eiffel, estruturada sobre os sonhos de progresso da modernidade, figura como fundo em torno do qual se levanta a cidade, como que acordada do sonho de progresso da modernidade.

Ao final do filme - cena analisada neste trabalho - Antoine corre ao encontro do mar enquanto seus olhos o contemplam. Como o fluxo e o refluxo das ondas, Antoine se volta com as mesmas para a praia e os seus olhos contra os nossos, fixando-os ao mesmo tempo em que se fixa a sua imagem no seu retrato - e o cinema se torna fotografia. Quando os olhos de Antoine contemplam o mar e, consequentemente, o jogo do fluxo e do refluxo das ondas, "o mar não é simplesmente o objeto privilegiado de uma plenitude visual isolada", como quando contemplado por um personagem moderno analisado por Georges Didi-Huberman (1998: 33). Não obstante, o momento em que os olhos de Antoine olham os nossos, mesmo momento em que o movimento do filme se interrompe, remete a outro, qual seja, "quando o fluxo da vida é represado, imobilizando-se", de modo que "essa interrupção é vivida como se fosse um refluxo: o assombro é esse refluxo" (BENJAMIN, 1994: 89).

Segundo Walter Benjamin, a montagem, como princípio formal, permite reconstruir a experiência - inviabilizada com a consolidação dos modos de produção capitalista - oferecendo visão para a reflexão. Para Benjamin, a montagem "interrompe o contexto em que se insere" e, assim, "age contra a ilusão" (BUCK-MORSS, 2002: 97). Uma crise cognitiva - inclusive do sujeito perceptivo proveniente de um lugar na modernidade no qual o sujeito "problematiza o que é" (CRARY, 2001: 71) - configurase no capitalismo tardio, promovendo uma desintegração da percepção, de modo que o capital torna-se um regime de atenção e distração - termos com os quais Benjamin (1989: 69) descreve a experiência moderna - e, ainda, uma mudança fundamental na relação do sujeito com o objeto (CRARY, 2001: 69). 
Benjamin louva o potencial cognitivo da experiência cultural tecnologicamente mediada, sobretudo do cinema, tanto que compreende que a tarefa da arte consiste em “desfazer a alienação do aparato sensorial do corpo, restaurar o poder instintual dos sentidos corporais humanos em nome da auto-preservação da humanidade" por meio da tecnologia. "O aparato técnico da câmera incapaz de 'devolver o nosso olhar"”, como afirma Susan Buck-Morss (1996: 12), apreende a indiferença dos olhos que a confrontam, "olhos que "perderam a capacidade de olhar"” (CRARY, 2001: 24). Em contrapartida, a assimilação da experiência mediante a tecnologia devolve sua sensibilidade caso o choque seja apreendido.

Para Benjamin, “as imagens elas mesmas - 'dialética em repouso' - são como disparos de uma câmera, que se 'revelam' no tempo", conquanto "o futuro possui reveladores ativos o suficiente para trazer estas placas perfeitamente para fora". Portanto, "essas imagens devem ser justapostas como em um filme", apontando para a “capacidade de 'choque' dessas imagens justapostas para provocar o despertar revolucionário" (BUCK-MORSS, 2002: 298-300). Assim, "se a industrialização causa uma crise na percepção pela aceleração do tempo e pela fragmentação do espaço, o filme mostra uma cura potencial ao desacelerar o tempo", afinal, o momento em que agora se estabelece a recepção do filme constitui um momento em que "a recepção cognitiva não é mais contemplativa, mas ligada à ação" (BUCK-MORSS, 2002: 323).

Por meio de um procedimento cognitivo similar ao da montagem, capaz de reconstituir a experiência a partir da sobreposição de imagens, pretendemos desvendar o olhar de Antoine. Para tanto, retornemos ao momento em que seus olhos olham os nossos, como que consolidando uma cena anterior em que, enquanto fotografado, Antoine parece impedido de olhar o espectador pelo personagem que opera a objetiva, potencializando a mediação do aparato entre os dois olhares:

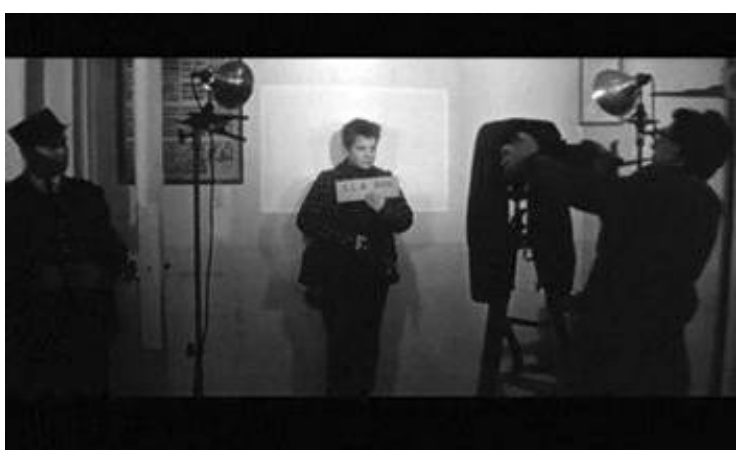

Fig 1: Antoine e o fotógrafo.

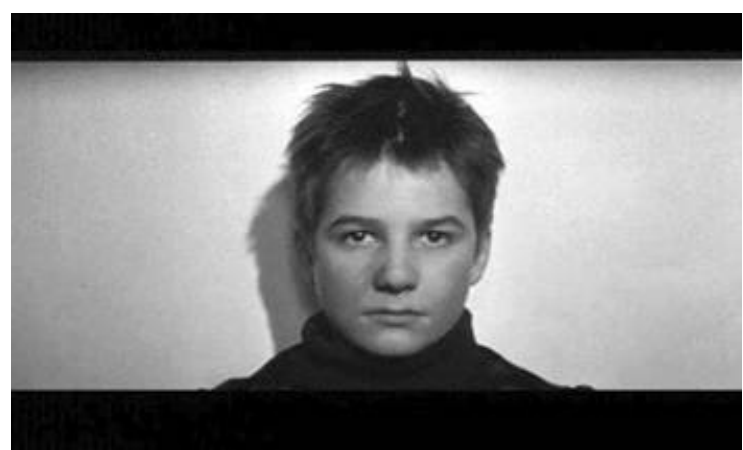

Fig 2: Antoine olha para a câmera. 


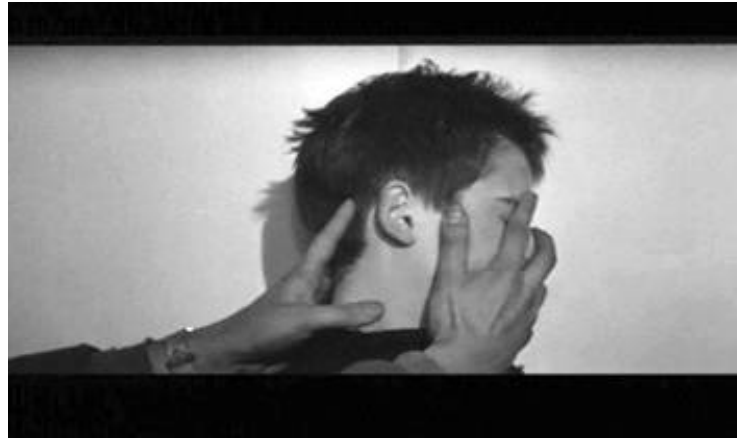

Fig 3: O fotógrafo intervém.

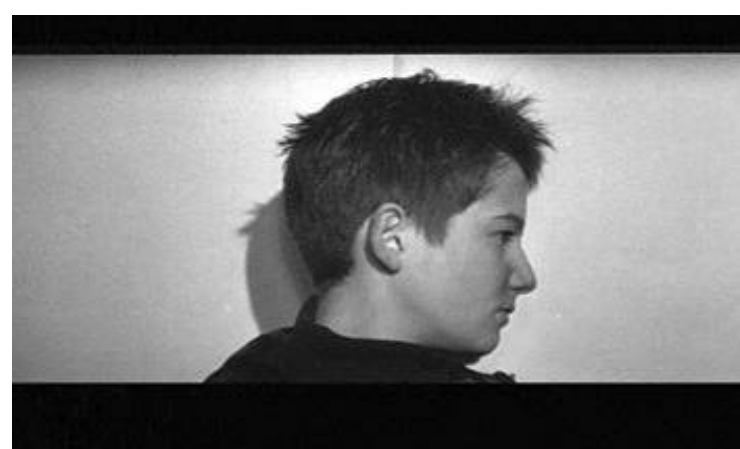

Fig 4: Antoine é impedido de nos olhar.

Dissemos que o momento em que, ao final, o movimento do filme se interrompe e, finalmente, Antoine nos olha nos olhos remete a outro, qual seja, "quando o fluxo da vida é represado, imobilizando-se", de modo que "essa interrupção é vivida como se fosse um refluxo: o assombro é esse refluxo" (BENJAMIN, 1994: 89).

O assombro mencionado por Benjamin (1994: 80) se relaciona com os conceitos de interrupção da ação, ou "efeito de retardamento da interrupção", e de distanciamento, associados ao teatro brechtiano. Segundo Benjamin, o teatro brechtiano conserva uma consciência de ser teatro, permitindo ordenar experimentalmente os elementos da realidade. Ao final do processo aparecem as condições representadas, afastadas do espectador, que as reconhece como reais com assombro.

O teatro brechtiano, cuja tarefa maior consiste em exprimir a relação entre a ação representada e a ação do ato mesmo de representar, descobre, portanto, as condições por meio da interrupção dos acontecimentos. O teatro brechtiano deixa as condições criticarem-se mutuamente, mediatica e dialeticamente, contrapondo uns aos outros os seus diversos elementos e revelando as contradições da ordem social.

Segundo Benjamin (1994: 84), nada impede de atribuir mais realidade ao personagem que o personagem representado, colocando o representado diante do real. Ora, o impacto provocado por esse processo condiz, na medida em que o confronto com o espectador o coloca diante de si mesmo, com o efeito produzido pelo olhar de Antoine. Olhar o espectador funda-o enquanto outro, sem, no entanto, permitir identificação, mas contradição, denunciando uma outra sensibilidade, qual seja, a do sujeito que olha.

Pode-se, portanto, supor que, como no teatro brechtiano, a interrupção da ação pretende ativar o espectador e, por meio do efeito de distanciamento, convencer o mesmo da necessidade de intervenção no movimento que permite nos tornar e a nossa condição objetos do nosso juízo crítico: 
A teoria do distanciamento é, em si mesmo dialética. (...) O distanciamento passa então a ser negação da negação; leva através do choque do não-conhecer ao choque do conhecer. Trata-se de um acúmulo de incompreensibilidade até que surja a compreensão. Tornar estranho é, portanto, ao mesmo tempo tornar conhecido. A função do distanciamento é a de se anular a si mesma (ROSENFELD, 2000: 152).

Nas palavras de Brecht, “distanciar é ver em termos históricos", o que implica o desdobramento em sujeito e objeto. (ROSENFELD, 2000: 155-160) Para tanto, recorrese a um modelo que permite analisar a relação entre a consciência burguesa e as condições sociais materiais, demonstrando os limites das teorias burguesas para conhecer a realidade.

A noção de que a estrutura de mercadoria se imprime no material implica entender que o material, ao menos segundo Theodor W. Adorno, compreende os problemas da sociedade, de modo que o intelectual e o artista, ao enfrentarem os problemas técnicos de sua disciplina, tratam, de forma mediatizada, dos problemas da totalidade social (BUCK-MORSS, 1981: 90). Contra o condicionamento decorrente do automatismo que provoca a incapacidade de compreensão, Adorno propõe um processo de desnaturalização permitido pela inserção do sujeito no universo da produção.

Segundo Adorno (1989), a discussão do artista com o material representa uma discussão com a sociedade, uma vez que o automovimento do material - que é dialético - se desenvolve no mesmo sentido que a sociedade real. Para tanto, uma subversão que consista na mudança de função da expressão de uma determinada arte por meio de choques que ficam registrados em seu meio material, atacando os tabus da forma, racionalizando-os e transpondo-os em imagens, atesta a impotência do homem, de modo que os choques se convertem na lei técnica da forma, proibindo toda continuidade e desenvolvimento.

A despeito das divergências entre Adorno e Benjamin, ambos parecem concordar quanto ao papel da interrupção enquanto uma forma de "parar o tempo (...) ou alcançar o passado, o tempo esquecido, para estilhaçar a superfície plácida do presente", como sugere Susan Buck-Morss (2001: 24). Buck-Morss (2001: 26) responsabiliza justamente os meios da arte pela sua opacidade, meios como fim em si mesmo, o que não permite que a arte seja reduzida a informação, justificando o seu 
poder e a sua impotência, como um meio, enfim, de devolver o valor de uso ao valor completamente subsumido pelo valor de troca.

Afinal, quando Benjamin (1994: 174) escreve que a sociedade moderna constitui a antítese da sociedade primitiva pela emancipação técnica, e que "essa técnica emancipada se confronta com a sociedade moderna sob a forma de uma segunda natureza, não menos elementar que a da sociedade primitiva, como provam as guerras e as crises econômicas", refere-se justamente a um retrocesso, pois a reprodutibilidade se caracteriza invariavelmente pela transitoriedade e repetibilidade, acarretando uma desumanização, de modo que ser defraudado da experiência se tornou o estado geral. E a lição de Adorno, por sua vez, consiste justamente em que o progresso pode sempre representar um retrocesso à barbárie.

Por outro lado, Adorno admite a "possibilidade de o cinema - mesmo o ideologicamente comprometido - atuar de modo libertador sobre as pessoas" a partir de uma apropriação "subversiva" dos seus modelos. E enxerga uma ligação imediata ao contexto social por meio da reprodução das imagens: “A estética do filme é, portanto, imanentemente social em virtude de sua posição para com a realidade externa" (DUARTE, 2003: 142-3). Mas, para tanto, Adorno entende que o estabelecimento de uma estética cinematográfica à altura do seu objeto implica procurar "o elo que liga as imagens fotografadas em movimento com o próprio movimento da consciência, com a interioridade consciente de si mesma", de forma que "chega a estabelecer uma linha demarcatória entre o cinema enquanto arte e como mero produto da indústria cultural a partir da possibilidade que ele tenha de externar as imagens da memória enquanto uma escrita imagética libertadora".

Apesar de compreender que o olho desempenha um papel de adaptação a uma ordem racional e burguesa ao se acostumar a conceber a realidade como composta de mercadorias, Adorno associa o sentido da visão a uma atitude humana voltada para o progresso, para o esclarecimento, que, no entanto, regride com a cultura massificada a partir de uma desconceitualização da linguagem visual. Portanto, a indústria cultural conserva uma "aura em decomposição", ao mesmo tempo em que oferece uma impressão de "estabilidade social e valorização do capital” (DUARTE, 2003: 118-33).

Não obstante, a interrupção do movimento das imagens do filme analisado, que constituem, antes de tudo, fotografias em movimento, uma vez destituídas do movimento, retornam ao estado de fotografia, de modo que a sua estaticidade evidencia a estaticidade da situação. Dessa forma, o filme remete ao conceito de "desmistificação" 
do teatro brechtiano, ou seja, revelação de que as condições sociais são históricas e, portanto, podem ser superadas (ROSENFELD, 2000: 150). Se no teatro brechtiano o espectador é solicitado a resolver os problemas da peça, os olhos de Antoine no filme não solicitam outra coisa.

A interrupção da ação no filme ocorre formalmente por meio da paralisação do movimento que caracteriza o cinema, de modo que a sequência final, entrecortada por apenas dois cortes, interrompe-se e se fecha no rosto de Antoine, como uma fotografia, consensualmente compreendida como um modo de parar o tempo, capaz de suscitar uma experiência singular e, desta forma, produzir uma visão. ${ }^{1}$

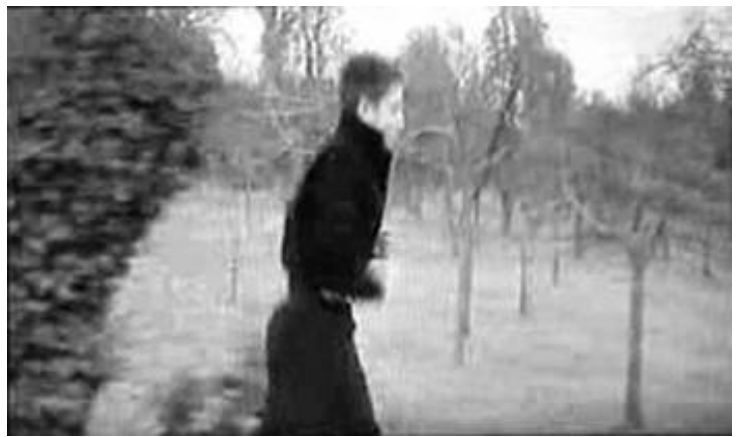

Fig 5: Antoine corre.

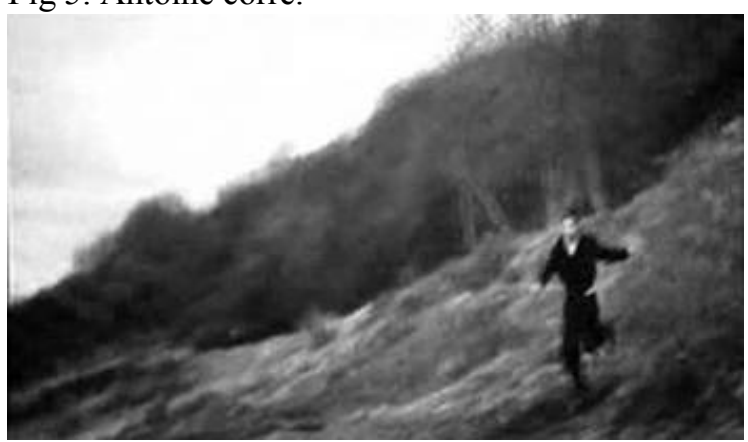

Fig 7: Antoine desce um penhasco.

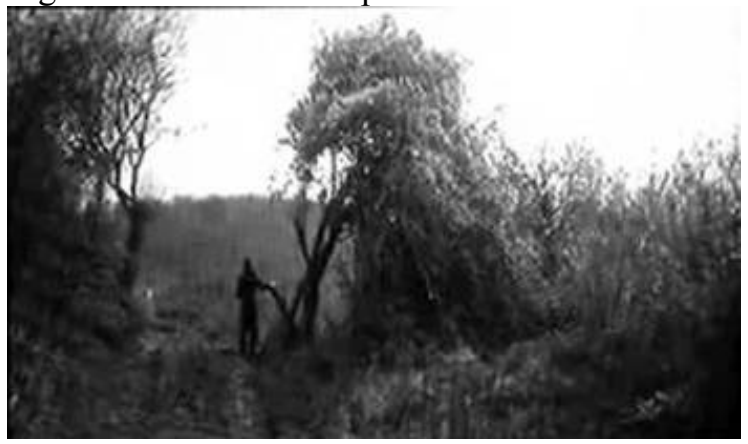

Fig 9: Antoine contempla o mar.

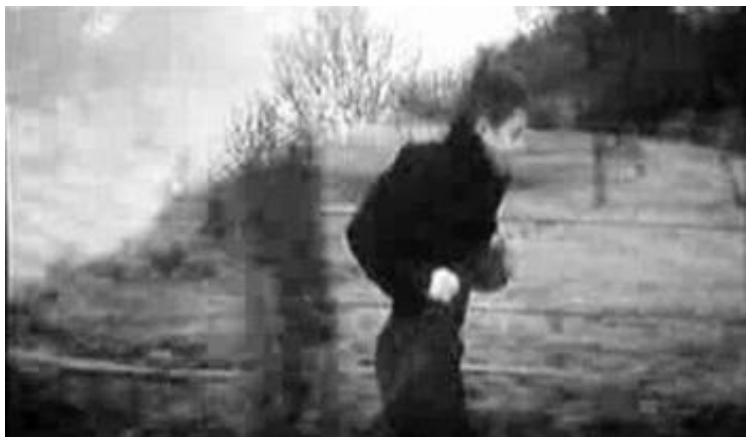

Fig 6: Encadeamento dos planos 1 e 2.

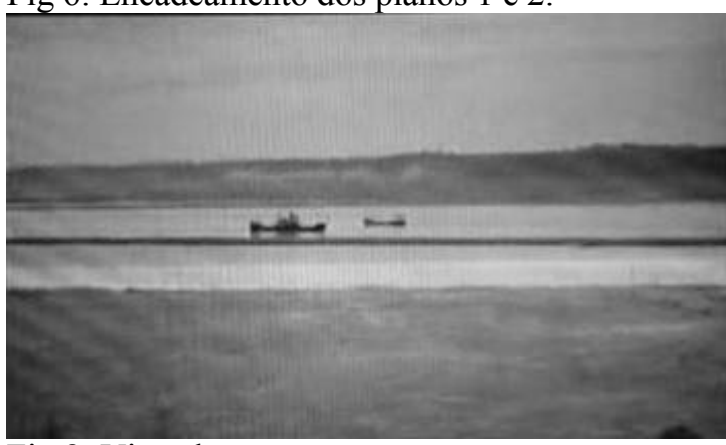

Fig 8: Vista do mar .

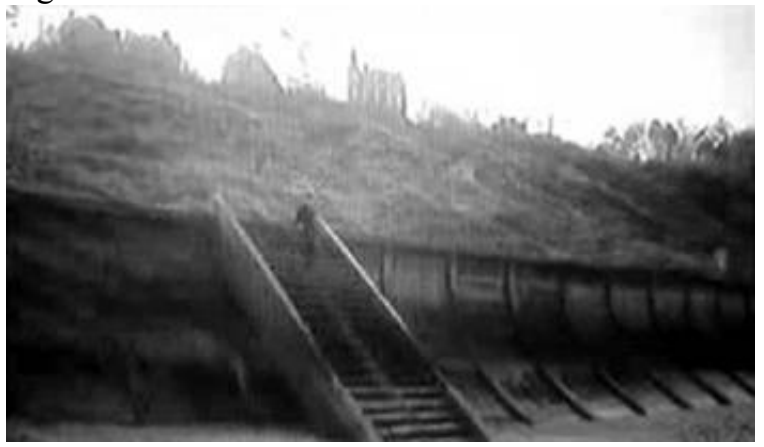

Fig 10: Corte. Antoine desce uma escadaria.

\footnotetext{
${ }^{1} \mathrm{O}$ procedimento capaz de produzir uma visão do objeto a partir da interrupção do movimento possibilidade vislumbrada por Benjamin na tecnologia - foi antecipada na literatura pelo formalismo russo de Victor Chklovski (Cf. CHKLOVSKI, 1973: 42-5).
} 


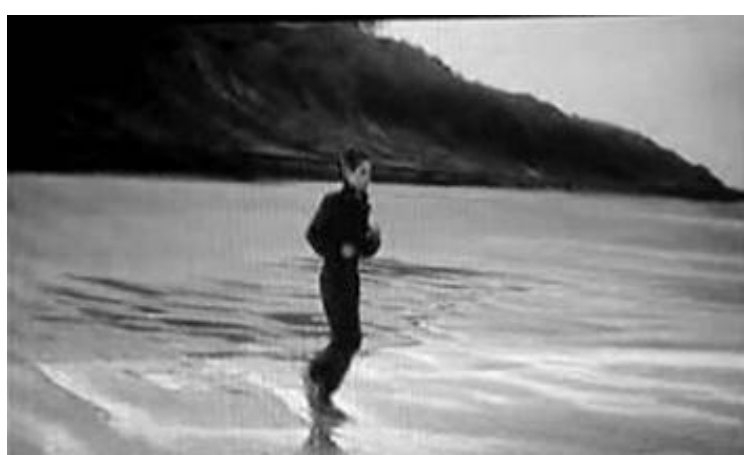

Fig 11: Antoine se aproxima do mar.

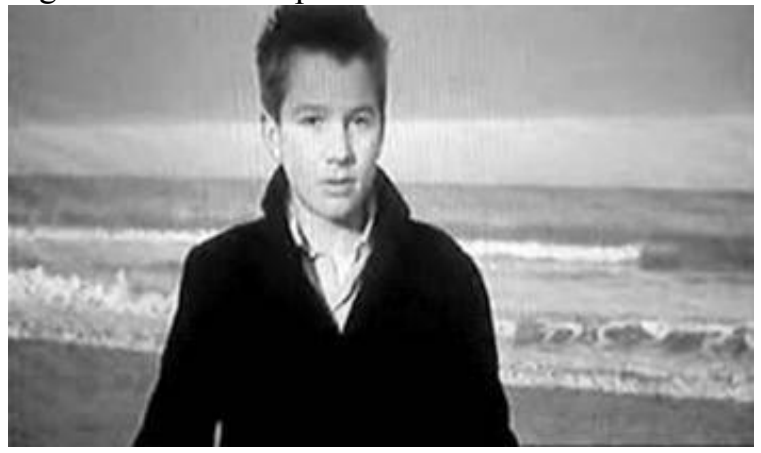

Fig 13: Antoine olha para a câmera e a imagem congela.

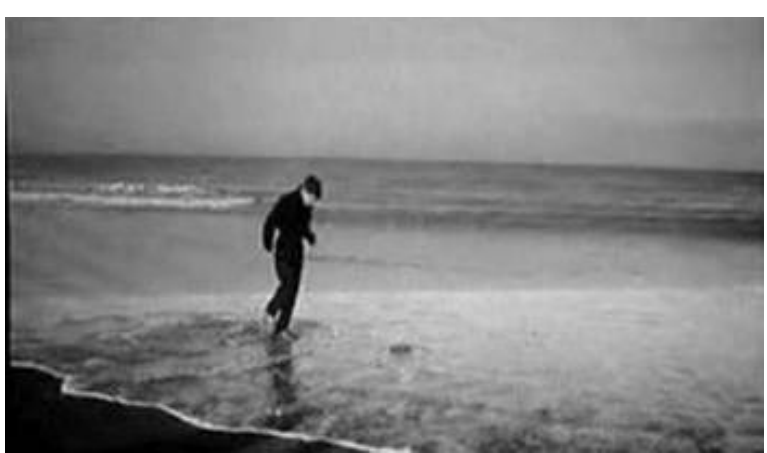

Fig 12: Antoine chega ao mar.

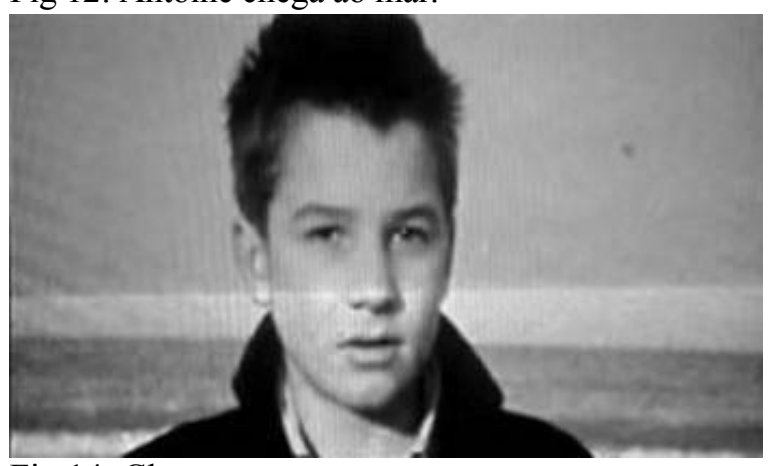

Fig 14: Close-up.

A paralisação do movimento no olhar do personagem sugere, ao mesmo tempo, um estado de devaneio, retomando o problema da atenção enquanto componente decisivo da modernidade. Se os olhos de Antoine não refletem por si mesmos a efemeridade da atenção como componente produtivo da modernização, refletem em si o "olho não fixo que está sempre na dobra entre a atenção e a distração", ou seja, o olho do espectador, refletido nos olhos do personagem no momento do "congelamento momentâneo da visão", “imobilização temporária em uma economia de fluxo e distração permanentemente instalada", revelando um presente impossível de ser apreendido (CRARY, 2001: 85-6).

Na medida em que a paralisação do movimento sugere um olhar apropriado para a fotografia, o filme remete aos problemas propostos a partir de uma outra linguagem, a da fotografia. Afinal, “a fotografia demonstra que o 'olho humano' percebe de maneira diferente o "cru olho inumano"” (BUCK-MORSS, 2002: 170), e o filme potencializa o poder de revelar o seu contexto humano na medida em que coloca o momento no movimento do seu contexto, o que o torna capaz de revelar o "inconsciente ótico" (BUCK-MORSS, 2002: 94) que escapa aos nossos olhos.

O olhar - enquanto meio do desejo - desempenha um papel tátil, relacionado com o fato de que "a visão se choca sempre com o inelutável volume dos corpos 
humanos", como afirma Didi-Huberman (1998: 30). Não obstante, Bataille (1968: 14) sugere uma relação entre a morte e a excitação sexual. Para o autor, o sentido fundamental da reprodução continua a ser a chave do erotismo: "entre um ser e outros seres (...) há uma descontinuidade", de modo que "tentamos comunicar mas nenhuma comunicação entre nós pode suprimir uma diferença primacial. Se morrerem, não sou eu que morro". Mas "podemos um comum (...) sentir a vertigem desse abismo. Esse abismo pode fascinar-nos. De certo modo, ele é a morte, e a morte é vertiginosa e fascinante".

A relação entre erotismo e morte se depreende dos olhos de Antoine na medida em que seus olhos remetem aos olhos dos seres objetificados - tornados objeto de desejo - em fotografias ou filmes de erotismo, cujos olhos nos olham nos olhos intermediados pela tecnologia. ${ }^{2} \mathrm{O}$ restabelecimento da relação entre erotismo e morte pretende justamente sustentar a verdade de que "o homem pode ultrapassar o que o aterra, pode olhá-lo de frente", como assegura Bataille (1968: 9), ao procurar desvendar o "horror ao olho" que caracteriza o homem civilizado, o olho que, segundo o autor, poderia ser aproximado do corte do cinema, e que, não obstante, "cumpre a função erótica da visão".

A mesma relação suscita ainda outros problemas propriamente modernos associados com a crise cognitiva que se configura na modernidade capitalista. $O$ "processo de fusão", compreendido como a conciliação entre sujeito e objeto, que descreve o processo cognitivo pretendido por Benjamin, relaciona-se com o movimento de dissolução dos seres proposto por Bataille (1968: 18) enquanto fusão em que finalmente os dois seres se confundam, de modo que "toda a consecução erótica tem por princípio a destruição da estrutura do ser fechado", implicando sujeito e objeto. Para tanto, a ação decisiva é o desnudamento, uma vez que a nudez opõe-se ao estado fechado, ou seja, ao estado de existência descontínua, equivalendo a uma morte violenta.

Nesse sentido, Bataille (1968: 18-33) afirma que "o erotismo é, na consciência do homem, o que o leva a pôr o seu ser em questão", de modo que "o seu conhecimento exige uma experiência pessoal, igual e contraditória, da proibição e da transgressão”. Portanto, "o que o erotismo implica é sempre uma dissolução das formas constituídas, ou seja, repetindo, das formas da vida social, regular, que fundam a ordem descontínua

\footnotetext{
${ }^{2}$ Conforme Willemen (1996: 212), o olhar proveniente da inversão da pulsão escópica induz vergonha no espectador na medida em que o prazer voyeur se torna desconforto.
} 
das individualidades definidas que somos". Para tanto, a sensualidade "pode realizar o que os nossos limites proíbem, ou seja, a plena confusão entre dois seres, a continuidade entre dois seres descontínuos". Não obstante, Michel Foucault (2001: 45) observa que a emergência da sexualidade em nossa cultura se associa a uma "forma de pensamento em que a interrogação sobre o limite substitui a busca da totalidade em que o gesto da transgressão toma o lugar do movimento das contradições".

Mas a relação entre o erotismo e a morte não se estabelece completamente sem que se considere que o erotismo moderno "abaixa as barreiras entre o mundo orgânico e o inorgânico", operando como a moda que, enquanto meio que seduz o sexo ao inorgânico - "o domínio das coisas mortas", "prostitui o corpo vivo degradando-o ao mundo inorgânico". É a "estação dialética de troca entre a mulher e a mercadoria - o desejo e o corpo morto" (BUCK-MORSS, 2002: 135). Benjamin afirma que a prostituta representa o emblema do capitalismo, associando-a ao trabalhador assalariado que se vende para sobreviver, de modo que a prostituta sintetiza a forma e o conteúdo da mercadoria. Ela é "mercadoria e venda de uma só vez". A prostituição representa a constatação de que "a mulher se torna artigo de massa" para a modernidade, apenas um “"tipo' tão repetitivo da cidade industrial como a mulher-mercadoria” (BUCK-MORSS, 2002: 227-35).

O "olho revirado", objeto da filosofia de Bataille, confunde-se, então, com o olhar de Antoine, revirado com o gozo "obtido com a visão da nossa própria destruição" (BUCK-MORSS, 1996: 12). Conjugam-se nos olhos de Antoine, portanto, os olhos exaustos dos sentidos, com os olhos da mulher objeto, que desaparece diante da "potência de estupefação da foto", que revela o "poder erótico de um mundo nulo". (BAUDRILLARD, 1997: 34-5). Afinal, os olhos da mulher objeto refletem uma "simulação desencantada: o pornô - mais verdadeiro que verdadeiro", "o máximo do simulacro", como afirma Jean Baudrillard (1997: 13-23).

O objeto que nos olha enquanto o olhamos exibe os meios pelos quais pode ser violado, mas seus olhos são opacos e incapazes de refletir aquele que o olha. Os olhos do corpo desnudado solicitam o toque do outro, impossibilitado pela intermediação da tecnologia, que nem mesmo reflete o desnudamento do outro. Por outro lado, outros olhos refletem os nossos ao projetar a condição do personagem analisado, tornando-a comum a toda a humanidade. Agora o objeto que nos olha nos permite ver vendo: o espectador se desloca para o lugar do personagem, cuja imobilidade reflete a impotência 
do espectador diante da sua condição, de modo que o objeto constitui, ao mesmo tempo, o sujeito.

A referida condição aparece representada por meio de uma suspensão do movimento, ao passo que o tempo permanece em movimento, de modo que as imagens das fotografias postas em movimento são outras mas são as mesmas. A suspensão do movimento corresponde ao momento da suspensão da encenação. O olho no olho revela que a "realidade" não é senão um mundo encenado (BAUDRILLARD, 1997: 18), o que o espectador reconhece como uma outra modalidade do "assombro" mencionado por Benjamin. O momento mencionado coincide com o cume da dramaticidade impresso na fotografia, conforme Baudrillard (1997: 33):

Pelo seu silêncio, pela sua imobilidade. É o que sonham as coisas, é o que nós sonhamos, não o movimento, é esta imobilidade mais intensa. Força da imagem imóvel, força da ópera mítica. O próprio cinema cultiva o mito da câmera lenta e do congelamento como o ponto mais alto da dramaticidade.

O despertar de um deslocamento da maneira de olhar - o que realmente importa para a obra de arte depois da era da reprodutibilidade - implica considerar que "a natureza que se dirige à câmera não é a mesma que se dirige ao olhar", pois " "penetra profundamente' no material", o que "se reveste de importância política, pois o mundo que se abre à câmera propicia conhecimentos relevantes para nele operar", de modo que "o cinema faz-nos vislumbrar, por um lado, os mil condicionamentos que determinam nossa existência, e por outro assegura-nos um grande e insuspeitado espaço de liberdade" (BUCK-MORSS, 2002: 320).

Para tanto, um procedimento de montagem como o do cinema permite entrever nos olhos de Antoine os "olhos vazios que não devolvem seu olhar" e, ao mesmo tempo, o que Benjamin antecipa como o que proporciona a aura por meio do que devolve o olhar, concepção a partir da qual Georges Didi-Huberman (1998: 29) desenvolve a verdade de que "aquilo que vemos vale - vive - apenas por aquilo que nos olha".

Didi-Huberman (1998: 34-7) estipula duas possibilidades conjugadas ao ato de ver, quais sejam, ter ou ser. A primeira estaria mais propriamente associada com o desejo suscitado pelo olhar, ao passo que a segunda, "quando ver é sentir que algo inelutavelmente nos escapa; isto é: quando ver é perder”. Esta modalidade da visão se relaciona com um objeto que mostra "a perda, a destruição, o desaparecimento dos 
objetos ou dos corpos". O vazio que os olhos de Antoine revelam apreende o que nos olha - a morte: "o destino do corpo semelhante ao meu, esvaziado de sua vida, de sua fala, de seus movimentos, esvaziado de seu poder de levantar os olhos para mim".

E, no entanto, a atitude de recusa ao que nos olha no que vemos, compreendida por Didi-Huberman (1998: 39) como o poder da linguagem sobre o olhar, parece inviabilizada, pois o que significa reconhecer que o que nos olha constitui apenas um filme é antecipado pelo distanciamento evocado pelo olhar. Desta forma, a indiferença, ou seja, a recusa da aura dos objetos por meio da ostentação de um modo de indiferença quanto ao que se esconde no olhar, parece abalada pela semelhança do que nos olha. $\mathrm{O}$ que nos olha no que olhamos nos olhos do personagem parece dobrado pela inscrição da palavra fim ao final do filme, pois é o fim o que vemos no que nos olha, o fim do filme com o olhar nos nossos olhos: "o que é visto, aqui, sempre se prevê; e o que se prevê sempre está associado a um fim dos tempos: um dia - um dia em que a noção de dia, como a de noite, terá caducado" (DIDI-HUBERMAN: 1998: 48). E, não obstante, como sugere Benjamin a respeito do romance, a palavra fim "convida o leitor a refletir sobre o sentido de uma vida" (BENJAMIN, 1994: 213).

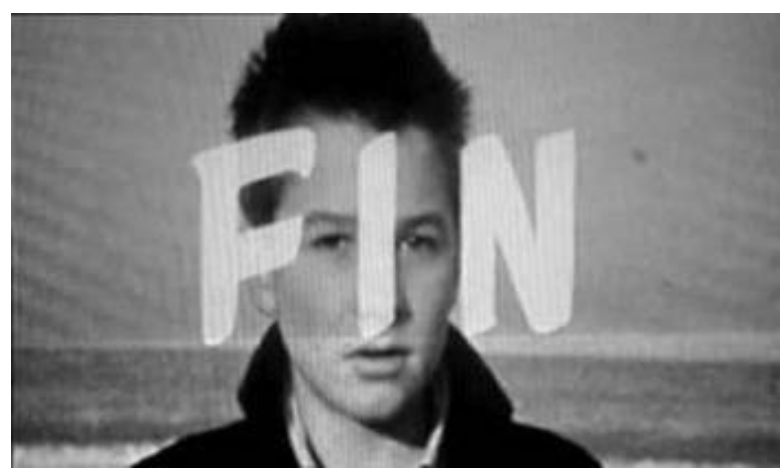

Fig 15: Fim.

\section{REFERÊNCIAS}

ADORNO, Theodor W. Filosofia da nova música. Trad. Magda França. $2^{\mathrm{a}}$ ed. São Paulo: Perspectiva, 1989.

BATAILLE, Georges. História do olho. Trad. Eliane Robert Moraes. São Paulo: Cosac Naify, 2003. 
O erotismo. Tradução de João Bénard da Costa. Rio de Janeiro: Moraes,

1968.

BAUDRILLARD, Jean. A arte da desaparição. Trad. Anamaria Skinner. Rio de Janeiro: Editora UFRJ, 1997.

BENJAMIN, Walter. Charles Baudelaire: um lírico no auge do capitalismo. Trad. José Martins Barbosa, Hemerson Alves Baptista. São Paulo: Brasiliense, 1989. (Obras escolhidas; v. 3)

Magia e técnica, arte e política: ensaios sobre a literatura e história da cultura. Trad. Sérgio Paulo Rouanet; prefácio Jeanna Marie Gagnebin. $7^{\text {a }}$ ed. São Paulo: Brasiliense, 1994. (Obras escolhidas; vol.1)

BUCK-MORSS, Susan. Dialética do olhar: Walter Benjamin e o Projeto das Passagens. Trad. Ana Luiza Andrade. Belo Horizonte: Editora UFMG; Chapecó: Argos, 2002.

. 'Estética e anestética: o 'ensaio sobre a obra de arte' de Walter Benjamin reconsiderado." In: Travessia - Revista de literatura - n. 33. Florianópolis, ago.-dez., 1996. (p. 11-41)

. “O que é arte política?” In: Revista Grifos - n. 10. Chapecó, junho, 2001.

(p. 15-27)

Origen de la dialética negativa: Theodor W. Adorno, Walter Benjamin

y el Instituto de Frankfurt. Tradução: Norta Rabotnikov Maskivker. México: Siglo XXI, 1981.

CHKLOVSKI, Victor. “A arte como procedimento”. In: TOLEDO, Dionísio de (org.). Teoria da literatura: formalistas russos. Porto Alegre: Globo, 1973.

CRARY, Jonathan. "A visão que se desprende: Manet e o observador atento no fim do século XIX.” In: CHARNEY, Leo; SCHWARTZ, Vanessa R. (Org.) O cinema e a invenção da vida moderna. São Paulo: Cosac \& Naify, 2001.

DIDI-HUBERMAN, Georges. O que vemos, o que nos olha. Trad. Paulo Neves. São Paulo: Ed. 34, 1998.

DUARTE, Rodrigo. Teoria crítica da indústria cultural. Belo Horizonte: Ed. UFMG, 2003. (Humanitas)

FOUCAULT, Michel. "Prefácio à Transgressão". In: Ditos e escritos III - Estética: literatura e pintura, música e cinema. Rio de Janeiro: Forense Universitária, 2001.

MORAES, Eliane Roberto. "Um olhar sem rosto". In: BATAILLE, Georges. História do olho. Trad. Eliane Robert Moraes. São Paulo: Cosac Naify, 2003. 
ROSENFELD, Anatol. O teatro épico. São Paulo: Perspectiva, 2000.

WILLEMAN, P. Voyeurism the Look and Dwoskin. In: ROSEN, P. (org). Narrative, Apparatus, Ideology: A Film theory reader. New York, Columbia University Press, 1986, p. 210-218.

\section{FILMOGRAFIA}

LES QUATRE cent coups. Direção: François Truffaut. Intérpretes: Jean-Pierre Léud, Claire Maurier, Albert Rémy. Roteiro: François Truffaut e Marcel Moussy. França, 1959. 